\title{
MOBILE LEARNING MENGGUNAKAN METODE PENGENDALIAN BAHAN AJAR (STUDI KASUS : MATA KULIAH SISTEM OPERASI)
}

\author{
Indra Listiawan ${ }^{1}$, Zaidir ${ }^{2}$ \\ Program Studi Manajemen Informatika \\ Universitas Respati Yogyakarta \\ indra.unriyo@gmail.com ${ }^{1}$, zaidirtan@gmail.com²
}

\begin{abstract}
Starts with the development of e-learning with simple technology to social network based on technology such as Edmudo. Because mobile phone users are very large more than two times the internet users, then some experts try to develop a model of learning with mobile phones.The problem is how to give a strong motivation for students to want to use mobile technology in teaching and learning process. This proposed research will create a mobile learning application combined with the control of teaching materials with the aim to increase student enthusiasm to obtain advanced materials after completing the existing material.Outcome to be achieved from this research is the contribution of research in the form of carelearning application with teaching material control method. This study focuses more on the side of instructional media or applications than with the content. Further research involving what form of content appeals to students still needs to be done as a future work of this research.
\end{abstract}

Keywords : Mobile Learning, e-learning, internet, learning and teaching

\section{Pendahuluan}

Diperkirakan jumlah pengguna handphone di seluruh dunia lebih dari 300 juta, dua kali lipat dari jumlah pengguna internet. Salah satu hal terbaru dan signifikan dalam hal perubahan lingkungan belajar adalah permintaan mobilitas. Handphone menjadi populer di masyarakat dan sebagian besar orang-orang mampu membiayainya. Selain itu, pertumbuhan eksponensial dari jaringan nirkabel dan mobile membawa perubahan besar dalam perangkat mobile, protokol pengembangan, standardisasi dan implementasi jaringan, dan penerimaan pengguna. Pembelajaran dengan media handphone disampaikan melalui jaringan nirkabel. Hal ini mendorong teknologi beradaptasi dengan cepat untuk memenuhi perubahan kebutuhan belajar. Dengan demikian dimungkinkan bagi peserta didik untuk menemukan dan belajar hal-hal yang mereka inginkan dengan cepat. Peserta didik mobilelearning(m-learning) dapat berkolaborasi dengan dosen dan peserta didik lainnya sehingga proses belajar dapat lebih baik.Teknologi m-learning dapat memberikan bahan dalam format multimedia pembelajaran secara cepat dan biaya yang lebih murah untuk mengajar peserta didik yang membutuhkan.

Berbagai macam media pembelajaran telah digunakan oleh pakar pendidikan dan teknologi informasi. Bermula dengan dikembangkannya e-learning dengan teknologi sederhana hingga teknologi berbasis jejaring sosial seperti Edmudo. Oleh karena pengguna handphone sangat besar hingga lebih dari dua kali pengguna internet ,maka beberapa pakar mencoba untuk mengembangkan model pembelajaran menggunakan media handphone.

Permasalahannya adalah bagaimana memberi motivasi yang kuat bagi mahasiswa agar mau menggunakan teknologi mobile dalam peroses belajar mengajar. Penelitian yang diajukan ini akan membuat sebuah aplikasi mobile learning yang dipadukan dengan pengendalian bahan ajar dengan tujuan untuk meningkatkan rasa keingintahuan mahasiswa segera mendapatkan materi lanjutan setelah menyelesaikan materi yang ada. 


\section{Landasan Teori}

Conaetha dalam penellitiannya melakukan beberapa metode untuk diterapkan di perkuliahan sekaligus melakukan evaluasi empiris tentang efektivitas Mlearning di kelas. Seratus dua belas siswa dalam ikut dalam survei pendahuluan dalam sosiologi diberi kesempatan untuk menggunakan produk MLearning yang dikembangkan oleh Perangkat Lunak HotLava untuk membantu mereka dalam persiapan untuk dua ujian yang dijadwalkan [8].

Menurut penelitian Lakshman, teknologi mLearning yang diusulkan memiliki kemampuan mempresentasikan secara langsung materi perkuliahan.Namun, cara perkuliahan yang ditayangkan berbeda dengan model pembelajaran tradisional [7].

Penggunaan mlearning ini dibahas Hobart dalam penelitiannya di bidang pendidikan. Mlearning ternyata akan mengkaitkan secara pedagogis konteks pembelajaran, menimbulkan konteks yang lebih luas beserta kontennya, sambil memberikan fasilitas personalisasi dan keterhubungan sosial di mana-mana. Peneliti membuat sebuah kasus yang sebagai dampak mlearning yang bertindak sebagai katalisator untuk mengubah model pembelajaran.Diinformasikan oleh peneliti ada lebih dari 30 proyek pembelajaran, dan mencerminkan contoh implementasi mlearning dalam berbagai konteks [12].

Menurut Kiger Dani perlu adanya penelitian eksperimental untuk menilai efek pencapaian jangka panjang bagi beragam kelompok siswa dan aturan sekolah dan untuk mengeksplorasi bagaimana pengajaran dan pembelajaran terjadi di lingkungan mobile di atas dan di luar perangkat tertentu [6].

Sedangkan menurut Martin F dkk teknologi mobile akan membuka pintu metode pembelajaran baru. Saat peserta didik memiliki akses terhadap informasi kapan saja dan dimana saja, peserta didik dapat melakukan aktivitas pembelajaran mereka. Tujuan dari penelitiannya adalah untuk mengetahui sejauh mana pengaruh teknologi mobile learning terhadap prestasi dan sikap siswa [9].

Marwan dkk menyajikan pengenalan teknologi pembelajaran mobile antar siswa di Kolej Poly-Tech MARA (KPTM) menggunakan ponsel. Mobile Learning (M-Learning) adalah konsep baru dalam proses pembelajaran yang menekankan kemampuan untuk memfasilitasi proses pembelajaran tanpa terikat dengan lokasi pembelajaran fisik [14].

Pembelajaran mobile relatif baru, tetapi Amrithal dkk melihat potensi perangkat mobile dalam pembelaaran dan adanya dukungan kinerja. Penelitian dimulai dengan memperkenalkan Teknik pembelajaran dan peralatan yang berbeda kemudian diperkenalkan Mobile mempelajari kelebihan, kekurangan, dan bagaimana dampak Mobile Learning di perguruan tinggi [4]

Penelitian telah menunjukkan bahwa dengan menggunakan teknologi mobile benar-benar dapat melibatkan peserta didik dan menciptakan hasil belajar yang positif [10] terutama siswa dari tingkat kemampuan yang lebih rendah dan menengah paling mendapat keuntungan dari m-learning . Berbagaisumber belajar dan ketersediaan aplikasi seperti text-to-speech, e-reader menawarkan berbagai kemungkinan baru bagi siswa yang punya ketidakmampuan.

Athanasios dkk memiliki gagasan memasukkan sistem mobile learning dalam proses pendidikan. Beberapa studi kasus penting terdapat dalam penelitian ini yang menguji konsekuensi penggunaan alat dan aplikasi seluler, serta aplikasi online dalam pengajaran matematika, pada semua tingkat pendidikan [5].

Penelitian yang dilakukan Rana menyajikan peluang dan prospek menggunakan m-learning untuk proses pembelajaran. Selain itu penelitiannya membahas tantangan dan dampak yang dihadapi dalam implementasinya. Penelitian dilakukan di Kuwait HE untuk menguji persepsi dan sikap siswa beserta instruktur terhadap penggunaan mlearning dalam proses pembelajaran, kemudian peneliti mengevaluasi keefektifannya, dan menyelidiki tantangan budaya dan sosial yang mempengaruhi penerapan m-learning di Kuwait. [2]

Alhasan dkk melakukan penelitian mlearning dengan tujuan untuk mengeksplorasi sikap, tingkat kesiapan dan hambatan yang mungkin ada dalam penerapan Mobile Learning sebagai bagian dari pembelajaran. Selain itu, penelitian ini mencoba untuk mengetahui sejauh mana siswa tertarik untuk belajar mobile. Penelitian ini juga bertujuan untuk menjawab pertanyaan tentang kesiapan mahasiswa menggunakan teknologi mobile learning [3]. 


\section{Perancangan Sistem}

Penelitian dilakukan di Program studi Manajemen Informatika Fakultas Sains dan Teknologi Universitas Respati Yogyakarta. Data yang digunakan sebagai sampel adalah materi kuliah Sistem Operasi.

\subsection{Tahap Penelitian}

Tahap penelitian yang dilakukan adalah sebagai berikut:

a) Menentukan kebutuhan sistem

Kebutuhan sistem dapat dibagi dua yaitu perangat keras dan perangkat lunak

b) Tahap pengumpulan data

Pengumpulan data dilakukan dikampus Universitas Respati di Program Studi Manajemen Informatika. Data yang dikumpulkan adalah materi kuliah sistem operasi sebagai sampel data.

c) Tahap Pengembangan sistem

Untuk mengembangkan sistem mobile learning, penelitian ini menggunakan metode Rapid Application Development(RAD) Metode RAD menurut Gottesdiener terdiri atas seperangkat alat serta manual yang dapat memfasilitasi pengembangan aplikasi dalam waktu singkat, yang berada dalam kerangka waktu yang telah ditentukan atau "timebox."Keuntungan dari RAD terbukti, karena fokusnya pada pengiriman cepat dan komunikasi pengembang-klien yang efektif, walau maih ada sejumlah masalah melalui pendekatan ini. Salah satu kelemahan yang paling jelas adalah bahwa hal itu menghilangkan banyak tekanan pada menit-menit perencanaan dan pemodelan pada awal proyek. [1].

Sehingga tahapan RAD dapat dirinci sbb:

1) Pembuatan prototipe

Prototipedibangun dengan memasukkanpersyaratan, mengkonversi informasi kebutuhan ke model data, mengubah model data ke database, dan menghasilkan kode semua dalam satu perangkat.

2) Pengembangan berulang

Pengembangan berulang yang berarti menciptakan versi yang semakin fungsional dari suatu sistem dalam siklus pengembangan yang singkat. Setiap versi diperlukan ulasan atau review dari klien.

3) Time Boxing

Time boxing adalah proses menonaktifkan fitur untuk versi aplikasi yang akan datang agar dapat menyelesaikan versi aplikasi saat ini dalam waktu yang singkat. Waktu yang sangat ketat adalah aspek penting dari RAD.

4) Keanggotaan Team

RAD membutuhkan tim kerja yang solid walaupun tidak memiliki anggota yang banyak dengan pembagian tugas yang tepat dan jelas.

Skema pengembangan aplikasi dengan metode RAD diperlihatkan pada Gambar $1[1]$.

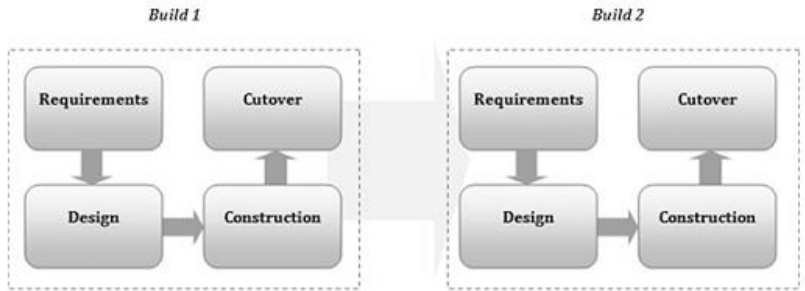

Gambar 1. Skema pengembangan aplikasi dengan metode RAD 


\subsection{Rancangan Sistem}

Sedangkan rancangan aplikasi yang akan dikembangkan dapat digambarkan melalui beberapa tahap desain:

\subsubsection{DesainUse Case}

a) Use Case Pengelolaan User diperlihatkan Gambar 2.

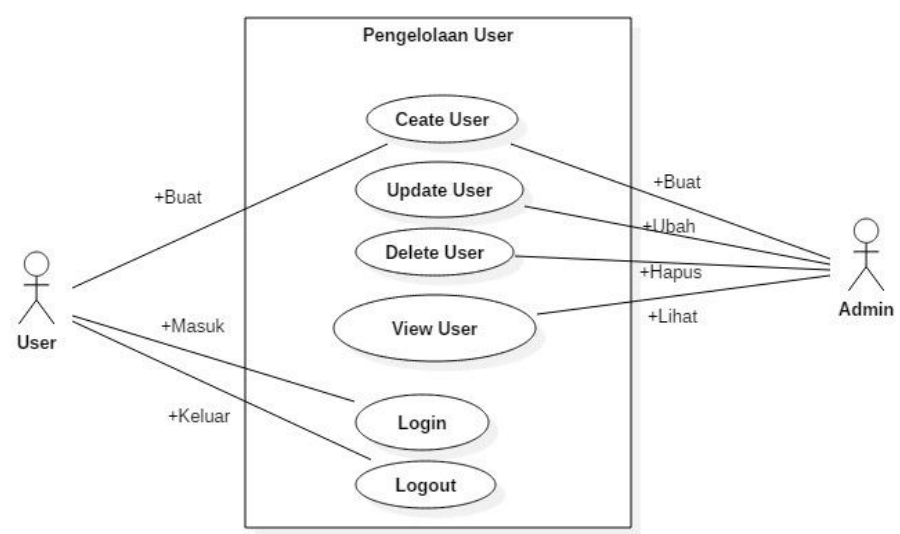

Gambar 2. Use Case Manajemen User

Use Case Pengelolaan User memperlihatkan dua pengguna dengan otoritas yang berbeda yaitu User Admin dengan otoritas membuat user, mengubah user, melihat user dan menghapus user, sedangkan pengguna lainnya yaitu dosen atau mahasiswa yang hanya mempunyai otoritas membuat account, login dan logout sistem

b) Use Case Pengelolaan Bahan Ajar

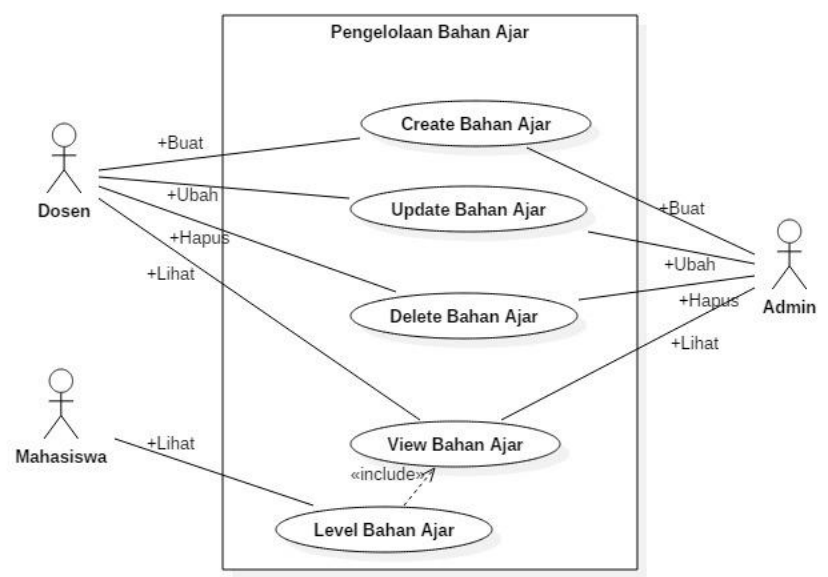

Gambar 3. Use Case Pengelolaan Bahan Ajar

Use Case pengelolaan bahan ajar melibatkan tiga pengguna dengan tiga otoritas yang berbeda yang pertama adalah admin dapat melakukan pembuatan bahan ajar, pengubahan bahan ajar, melihat bahan ajardan penghapusan bahan ajar. Pengguna lainnya adalah dosen yang diberi otoritas membuat bahan ajar, melihat bahan ajardan mengubah bahan ajar, sedangkan pengguna mahasiswa dapat melihat bahan ajaryang bergantung pada level bahan ajar. Level bahan ajaryang lebih tinggi tingkat kesukarannya tidak dapat diakses mahasiswa bilamana level bahan ajaryang dibawahnya belum selesai diakses oleh mahasiswa. Dalam use case pengelolaan materi ini terlihat pengendalian bahan ajar berupa fungsi validasi sistem. Dengan adanya fungsi validasi mahasiswayang belum menyelesaikan latihan soal pada level yang lebih rendah tidak akan dapat membuka bahan ajarpada level yang lebih tinggi. 


\subsubsection{Desain Usecase Scenario}

1. Desain Use Case Scenario Menampilkan dan mengelola Mata Kuliah

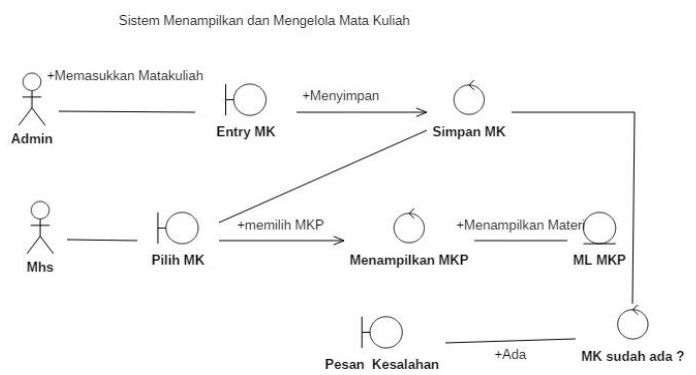

Gambar 4. Use Case Scenario Menampilkan dan Mengelola Mata Kuliah

2. Use Case Scenario Pendaftaran Peserta Mobile Learning

Pendaftaran Peserta Mobile Learning

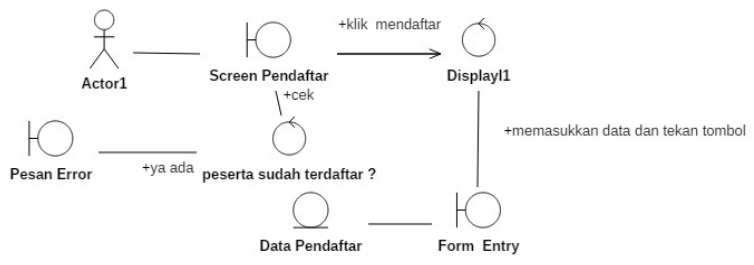

Gambar 5. Use Case Scenario Pendaftaran Peserta Mobile Learning

3. Use Case Pelaksanaan Ujian

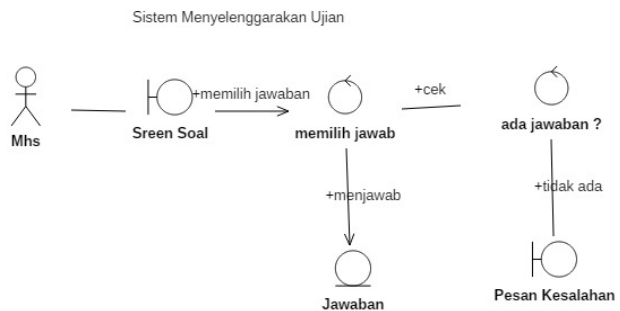

Gambar. 6 Use Case Scenario Pelaksanaan Ujian

\subsubsection{Desain Sequence Diagram}

Desain Sequence Diagram merupakan urutan kegiatan yang dilakukan sistem. Adapun desain Sequence Diagram pada penelitian ini adalah :

1. Diagram Sequence menampilkan Mata Kuliah Pilihan

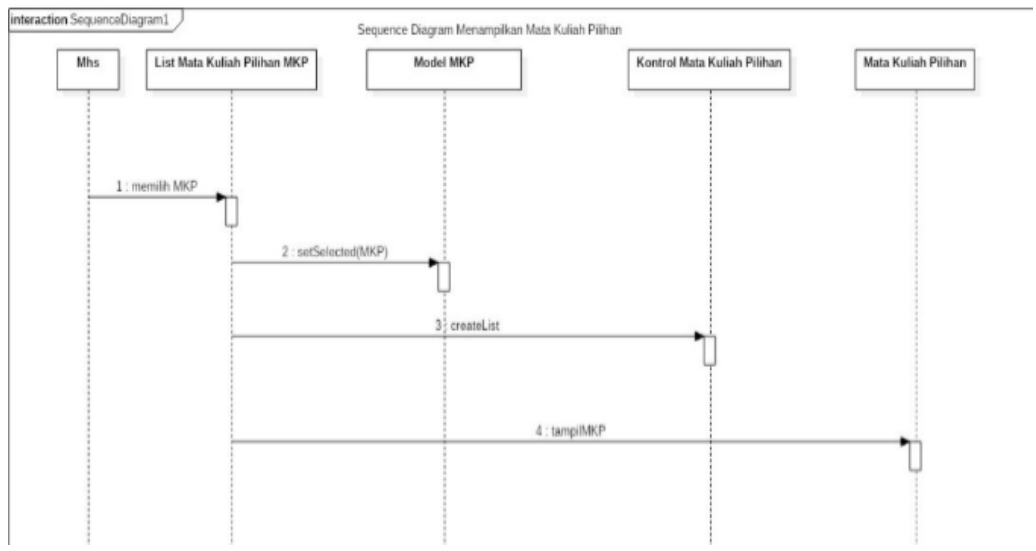

Gambar 7. Sequence Diagram Menampilkan Mata Kuliah 
2. Diagram Sequence menampilkan Materi Kuliah

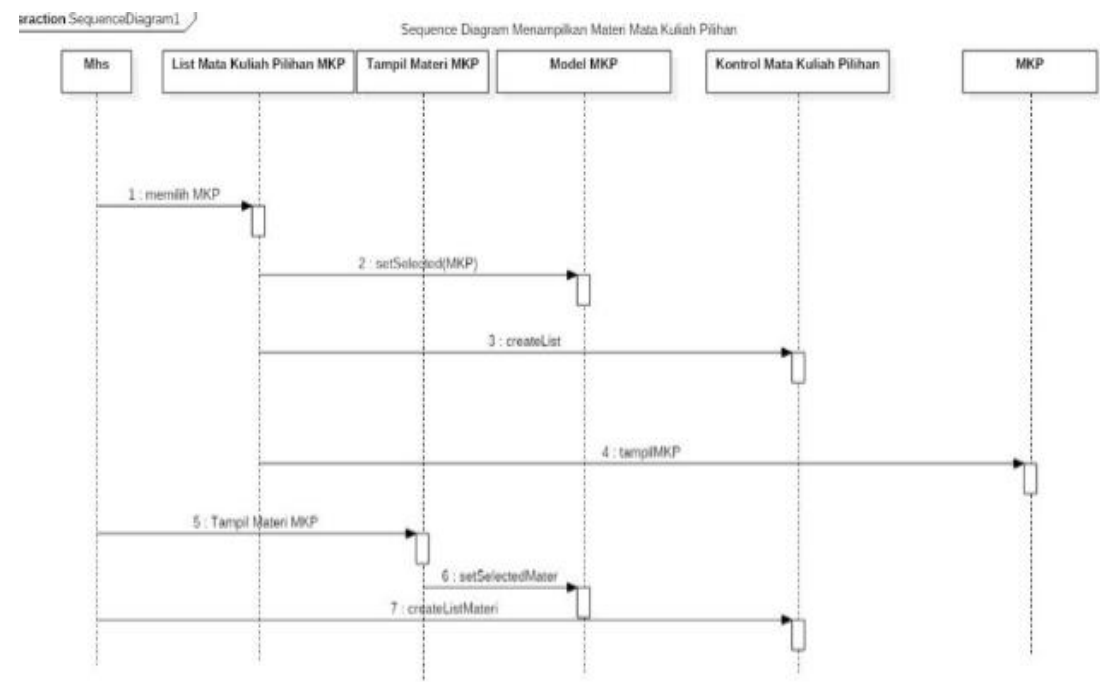

Gambar 8. Sequence Diagram Menampilkan Mata Kuliah

3. Diagram Sequence Pelaksanaan Ujian

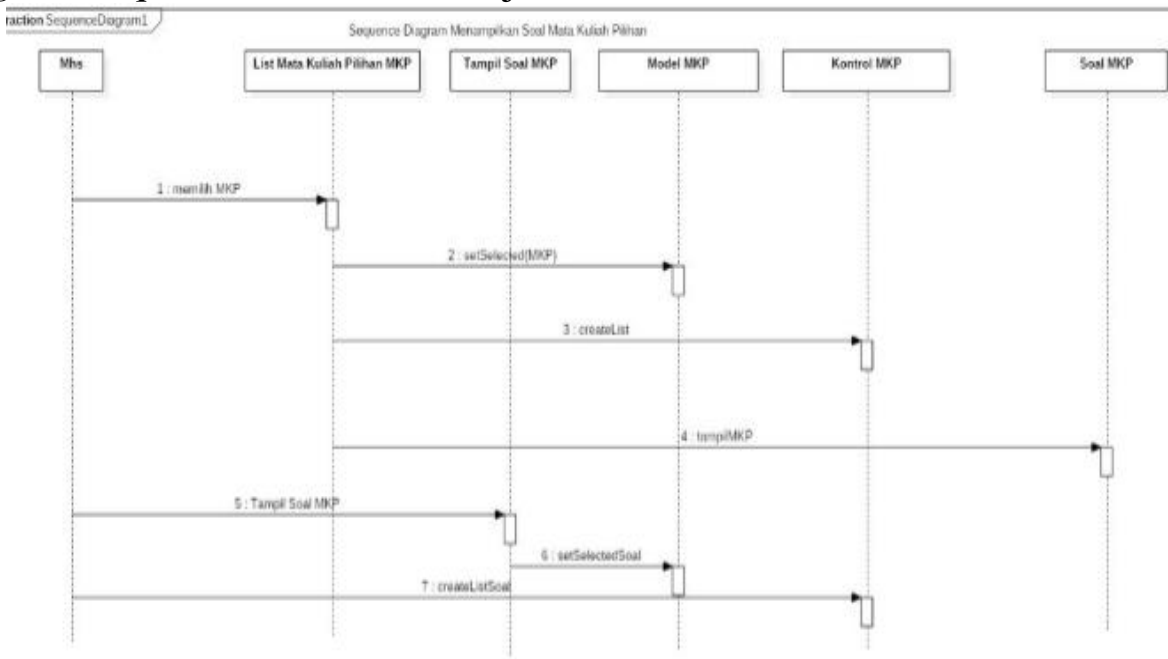

Gambar 9. Sequence Diagram Pelaksanaan Ujian

\subsubsection{Desain Class Diagram}

Desain Class Diagram diperlukan untuk merancang class pembentuk objek atau instan pada sistem. Gambar 10 menunjukkan desain Class Diagram pada sistem yang dikembangkan



Gambar 10. Class Diagram Sistem Pembelajaran Online 


\subsubsection{Algoritma Pengendalian Bahan Ajar}

Agar aplikasi mobile learning dapat mengendalikan pengguna saat melakukan perpindahan materi kuliah maka diterapkan algoritma sebagai berikut:

1) Periksa status halaman saat ini

2) Bila halaman saat ini merupakan halaman soal maka,

3) Periksa apakah semua jawaban telah terisi pada kolom jawaban ditabel soal

4) Bila semua kolom jawaban sudah terisi maka pengguna dapat melanjutkan materi berikutnya.

5) Bila ada kolom jawaban yang belum terisi, maka tampil pesan "pengerjaan soal harap diselesaikan".

\section{Hasil dan Pembahasan}

Hasil penelitian yang berupa prototype software mobile learning. Software menggunakan framework ionic dengan database MySql. Software terbagi dalam lima antar muka (interface) yaitu

a) Tampilan Pembuka

b) Pendaftaran

c) Login

d) Pemilihan matakuliah

e) Materi Kuliah dan Soal

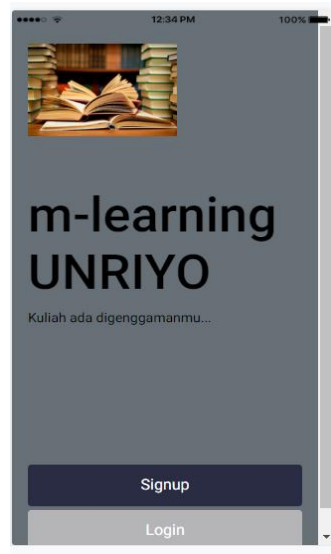

Gambar 11. Tampilan Pembuka

Terdiri dari dua tombol yaitu Signup untuk pendaftaran dan Login, bila tombol Signup ditekan maka akan tampil interface pendaftaran, sedangkan bila Login ditekan maka akan tampil interface Login



Gambar 12. Interface Pendaftaran

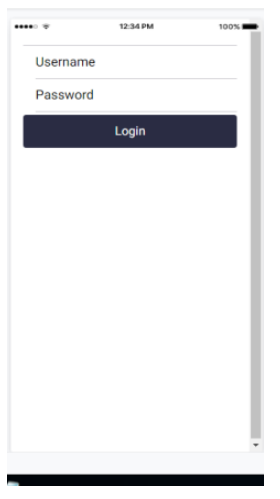

Gambar 13. Interface Login 
Interface pendaftaran terdiri atas empat field yang harus diisi sebelum seorang pengguna mendapatkan akun. Setelah pendaftaran akun maka pengguna dapat menuju interface Login untuk masuk ke media mobile learning.

Setelah pengguna memasukkan akun dan password maka pengguna yang berhasil Login dapat memasuki interface pilihan matakuliah beserta topik perkuliahannya. Topik ini akan menghubungkan pengguna ke interface materi kuliah beserta soal-soalnya.

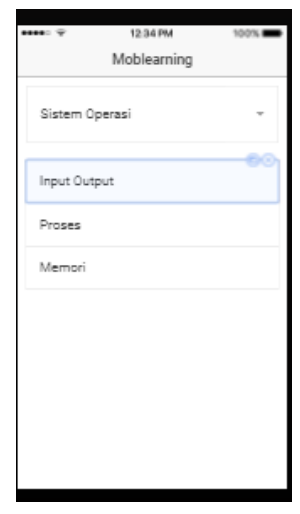

Gambar 14. Interface Pemilihan Matakuliah

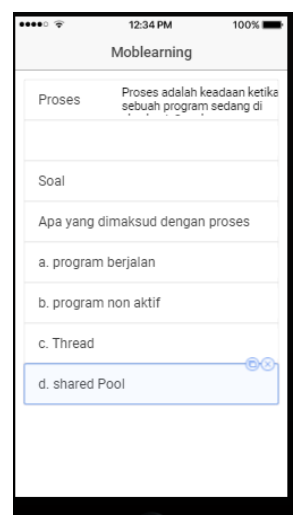

Gambar 15. Interface Materi Kuliah dan Soal

\section{Kesimpulan}

Penelitian mobile learning yang dilakukan lebih kepada pendalaman materi pemrograman mobile tim peneliti. Prototype yang dihasilkan masih harus dikembangkan sehingga menjadi aplikasi yang mudah dan nyaman digunakan. Beberapa fasilitas pada aplikasi ini perlu ditambahkan seperti penambahan jadwal kelas mobile, pencantuman score nilai, dan pembuatan subkelas.

Perlunya diujicobakan prototype ini kepada siswa pelajar SD maupun menengah agar pemanfaatan aplikasi menjadi lebih luas.

\section{Ucapan Terimakasih}

Penelitian ini dilakukan dalam skema Penelitian Dosen Pemula yang diadakan oleh Direktorat Riset dan Pengabdian Pada Masyarakat Direktorat Jendral Penguatan Riset dan Pengembangan Kementrian Riset dan Pendidikan Tinggi Republik Indonesia.

Tim peneliti mengucapkan terimakasih kepada Direktorat Riset dan Pengabdian Pada Masyarakat yang telah memberi kesempatan kepada tim peneliti untuk menambah wawasan dan pengetahuan melalui penelitian dalam skema ini. Semoga penelitian ini dapat membawa manfaat bagi kemajuan bangsa Indonesia.

\section{Daftar Pustaka}

[1] Agarwal, R., Prasad, J., Tanniru, M., \& Lynch, J. (2000). Risks of rapid application development. Communications of the ACM.

[2] Alhajri, R. (2016). Prospects and Challenges of Mobile Learning Implementation: A Case . Information Technology and Software Engineering.

[3] Alhassan, R. (2016). Mobile Learning as a Method of Ubiquitous Learning: Students' Attitudes, Readiness, and Possible . Journal of Education and Learning.

[4] Amritpal Kaur, Manpreet Singh Bhullar. (2013). A New Method of Learning: M-Learning (Mobile Learning). IAENG Proceedings of the World Congress on Engineering. 
[5] Athanasios S. Drigas, and Marios A. Pappas. (2015). A Review of Mobile Learning Applications for Mathematics. International Journal of Interactive Mobile Technologies.

[6] Derick Kiger Dani Herro Deb Prunty. (2012). Examining the Influence of a Mobile Learning Intervention on Third Grade Math Achievement. Research on Technology in Education .

[7] Dissanayake, L. (2009). mLearning: an innovative conceptualization to expand Education for everyone, anytime, everywhere. Working Papers on Information Systems.

[8] Douglas McConatha, Matt Praul, West Chester. (2008). Mobile Learning In Higher Education: An Empirical Assessment Of A New Educational Tool. The Turkish Online Journal of Educational Technology - TOJET.

[9] Florence Martin, Jeffrey Ertzberger. (2012 ). Here and now mobile learning: An experimental study on the use of. ScienceDirect Computers \& Education elsevier.

[10] Frederick Ako-Nai dan Qing Tan. (2013). Location-Based Learning Management System for Adaptive Mobile Learning. International Journal of Information and Education Technology.

[11] Gottesdiener, E. (1995). RAD realities: beyond the hype to how RAD really works. Application Development Trends.

[12] Hobart. (2011). mLearning: Why? What? Where? How? ascilite .

[13] Ismail Fayed,Amer Yacoub dan Ali Hussein. (2013). Exploring the Impact of Using Tablet Devices in. 12th World Conference on Mobile and Contextual Learning. Qatar.

[14] M.E. Marwan, Yousef Mehdipour, Hamideh Zerehkafi. (2013). An Overview Of Mobile Application In Learning For Student Of Kolej Poly-Tech Mara (Kptm) By Using Mobile Phone. Journal of Asian Scientific Research. 